\title{
Identification of Intrinsic Airway Acidification in Pulmonary Tuberculosis
}

\author{
Lina Ngamtrakulpanit \\ Bangkok Allergy and Asthma Center Bangkok Hospital \\ 2 Soi Soonvijai 7, New Petchburi Rd. \\ Bangkpk 10310, Thailand \\ E-mail: lina972@yahoo.com \\ Yuanlin $\mathrm{Yu}$ \\ Division of Pediatric Respiratory Medicine \\ Box 800386, University of Virginia \\ Charlottesville, VA 22908 \\ E-mail: yy4d@virginia.edu \\ Andrew Adjei \\ ${ }^{\wedge}$ University of Ghana Medical School, College of Health Sciences, University of Ghana \\ PO Box 4236, Accra, Ghana \\ E-mail: seth.ayettey@gmail.com \\ George Amoah \\ University of Ghana Medical School, College of Health Sciences, University of Ghana \\ PO Box 4236, Accra, Ghana \\ E-mail: seth.ayettey@gmail.com

\section{Ben Gaston} \\ Division of Pediatric Respiratory Medicine \\ Box 800386, University of Virginia \\ Charlottesville, VA 22908 \\ E-mail: bmg3g@virginia.edu \\ John Hunt \\ Division of Pediatric Respiratory Medicine \\ Box 800386, University of Virginia \\ Charlottesville, VA 22908 \\ E-mail: jfh2m@virginia.edu
}

\section{Abstract}

Exhaled breath condensate acidification reflects the presence of airway acidification. Mycobacterium tuberculosis is an organism particularly sensitive to acidity. We aimed to determine if there is evidence of airway acidification in a cross section of patients with active tuberculosis. 
We enrolled 51 subjects with active tuberculosis in Ghana and Thailand, and compared them to control subjects. We collected exhaled breath condensate, and assayed for $\mathrm{pH}$ after gas standardization.

Exhaled breath condensate $\mathrm{pH}$ from the control group revealed a median of $7.9(7.7-8.0, \mathrm{n}=21)$, significantly higher than the active pulmonary tuberculosis patients who had a median $\mathrm{pH}$ of $7.4(7.0-7.7 ; \mathrm{n}=51 ; \mathrm{p}=0.002)$. Presence or absence of antibiotic therapy did not affect EBC $\mathrm{pH}$ values.

These exhaled breath condensate data support the theory that airways become acidic in active tuberculosis infection. This may be a mechanism of immune response and pathology not previously considered.

Keywords: Exhaled breath condensate, Tuberculosis, Airway acidification, Breath diagnostics, Ghana, Thailand, Innate immunity

\section{Introduction}

Acidification of exhaled breath condensate (EBC) has been identified in multiple respiratory illnesses(J. Hunt, 2007), and is caused by acidification of the airway lining fluid at some level. The degree and precise location of airway acidification is uncertain, although invasive measures with $\mathrm{pH}$ probe in bronchi correlate well with EBC $\mathrm{pH}$ in a bovine lung model(Bunyan et al., 2005). Acidification of EBC is best considered as an indicator of airway acidification as opposed to a biomarker indicative of inflammation.

The induction of hundreds of genes in M. tuberculosis and M. avium paratuberculosis upon exposure to acid stress(Wu, Schmoller, Shin, \& Talaat, 2007) confirms that the $\mathrm{pH}$ of the microenvironment is sensed and responded to by these organisms. Despite acid-induced stress responses, survival of Mycobacterium tuberculosis is inhibited by an acidic environment(Piddington, Kashkouli, \& Buchmeier, 2000). Mycobacterial proteins are produced which attempt to alkalinize phagosomes of macrophages(Chicurel, Garcia, \& Goodsaid, 1988; Sturgill-Koszycki et al., 1994); indeed, Mycobacteria only survive if phagosomes do not acidify(Appelberg, 1994; Crowle, Dahl, Ross, \& May, 1991; Gomes et al., 1999; Jack et al., 1995). Acidification of phagosomes is an important innate immune mechanism(Krause, 2000), but with the recent recognition that the extracellular airway fluids can acidify in association with inflammatory and infectious diseases, the possibility arose that intrinsic airway acidification might also serve as a host response against Mycobacteria. If so, airway $\mathrm{pH}$ may be a therapeutic target, and its measurement serve as a biomarker of responses to active mycobacterial disease.

In order to determine if intrinsic airway acidification might play a role in pulmonary tuberculosis, we enrolled subjects with active tuberculosis in Ghana and Thailand and collected exhaled breath condensate for $\mathrm{pH}$ assessment as a non-invasive surrogate for the presence of airway acidity.

\section{Methods}

\subsection{Subjects}

Subjects and controls consisted of adults enrolled at the Chest Clinic of the University of Ghana Medical School, Accra, Ghana, and at the Chest Disease Institute, Department of Medical Service, Ministry of Public Health in Bangkok, Thailand. Both clinics were staffed by tuberculosis experts. EBC samples were collected from two groups of patients; one having active TB and another non-active TB, differentiated by mandatory sputum identification of acid-fast bacilli (AFB) staining in addition to clinical and radiographic findings. The active group consisted of those subjects whose current sputum examination was AFB positive. The non-active group were those subjects whose sputum previously was AFB positive, were undergoing anti-tuberculous treatment, and were subsequently sputum AFB negative. Controls were recruited from the same clinics and had no symptoms consistent with active pulmonary tuberculosis. Subjects provided written informed consent, and the studies were approved by the local institutional review boards, as well as by that of the University of Virginia.

\subsection{Exhaled breath condensate collection}

EBC was collected using the RTube system (Respiratory Research, Inc. USA) during oral tidal breathing for 7 minutes without nose clips. A 0.3 micron particle filter was placed between the mouthpiece and the condenser to prevent intact bacilli from entering the sample.

\section{3}

EBC $\mathrm{pH}$ assay was performed after gas-standardization with research grade Argon for 10 minutes (350 $\mathrm{ml} / \mathrm{min})$, at which point the $\mathrm{pH}$ (as measured by an Orion semimicro $\mathrm{pH}$ probe attached to an Orion meter [Beverly, MA, USA]) was persistently stable. This assay methodology has been validated and is generally considered the most reproducible assay in EBC(Horvath, Hunt, \& Barnes, 2005; Paget-Brown et al., 2006; Vaughan et al., 2003). 


\subsection{Statistical considerations}

Data are presented as median and interquartile range and mean \pm standard deviation where appropriate. Results of EBC pH assays among the groups were compared by Mann-Whitney Rank Sum or ANOVA on Ranks with Dunn's post-hoc testing using Sigmastat 3.0 software.

\section{Results}

We enrolled a total of 25 controls and 51 subjects with active tuberculosis. In Ghana, we enrolled 10 control subjects and 6 subjects with active pulmonary tuberculosis. In Thailand, we enrolled 15 control subjects and 45 subjects with tuberculosis (22 with negative sputum AFB and 23 subjects with a positive sputum AFB in whom anti-tuberculous therapy had not been yet initiated).

EBC $\mathrm{pH}$ from the control group revealed a median of 7.9 (7.7 - 8.0), significantly higher than the active pulmonary tuberculosis patients who had a median $\mathrm{pH}$ of $7.4(7.0-7.7 ; \mathrm{p}=0.002)$, but with $\mathrm{EBC} \mathrm{pH}$ values as low as 4.2 [Figure 1]. There were no differences identified based on whether or not patients had begun receiving active therapy. In the group receiving active therapy (with AFB-negative sputum on most recent sample; $n=28$ ), the median $\mathrm{EBC} \mathrm{pH}$ was 7.4 (6.9 - 7.6); for the as yet untreated patients, the median $\mathrm{EBC} \mathrm{pH}$ was similar: 7.5 $(7.0-7.8 ; n=23 ; \mathrm{p}=\mathrm{ns})$.

17 randomly selected samples from the enrolled subjects underwent repeat EBC $\mathrm{pH}$ assay several months after the initial assay had been performed (stored at $-20^{\circ} \mathrm{C}$ ) to investigate assay reproducibility. Consistent with previous reports, the repeated assays showed excellent reproducibility with $\mathrm{R}^{2}=0.975$. There was no difference in the $\mathrm{EBC} \mathrm{pH}$ values of any group based on whether female or male.

\section{Discussion}

Our data reveal that patients with active pulmonary tuberculosis in Ghana and Thailand have a higher incidence of EBC acidification than controls enrolled in the same area. Likewise, the median EBC in active pulmonary TB is substantially lower than all published historical controls as summarized in reference 12 (Paget-Brown et al., 2006). It is reasonable to conclude that airways commonly are acidic in active tuberculosis. It may also be the case that acid cough (cough reflexively triggered by acid in the airways) may contribute to the symptoms of tuberculosis.

We have no reason to suspect that tuberculosis itself would acidify extrathoracic/upper airway fluid $\mathrm{pH}$ (such as hypopharyngeal fluid). However, we did consider the possibility that drugs used to treat tuberculosis could conceivably cause such an effect. Our data, however, reveal no difference in EBC $\mathrm{pH}$ in a group of treated vs. untreated patients with pulmonary tuberculosis, helping to confirm that the effect seen was associated with the tuberculosis and not drug-induced. It is likely that this acidification is intrinsic to the airway, as opposed to reflecting gastric acid reflux and aspiration. In this regard, it has been shown that reflux can cause EBC acidification and cough, and acid can certainly cause cough, but that cough does not cause acid reflux sufficient to acidify EBC(J. Hunt et al., 2006). Additionally no salivary acidification was identified in the tuberculosis subjects in the Ghanaian cohort, in which salivary $\mathrm{pH}$ was measured concurrently with $\mathrm{EBC}$ (data not shown). Gastroesophageal acid aspiration could be contributing to the EBC pH effect, but then one would need to consider that tuberculosis infection increases reflux, which seems unlikely.

It has been suggested that EBC acidification may reflect inflammation causing airway acidification. However, we consider the obverse more likely: that the intrinsic ability of the airway epithelium to acidify in response to various insults(F. Acevedo, 2005; M. Acevedo \& Steele, 1993; Fischer, Widdicombe, \& Illek, 2002) may in part be initiated by Th1 cytokines(J. F. Hunt et al., 2002), and serves as an active and rapid innate immune response designed to injure invading pathogens and chemically attract and activate relevant immunologic components of the expanded innate immune system(Rabinovich, DeStefano, \& Dziezanowski, 1980; Trevani et al., 1999; Zigmond \& Hargrove, 1981). In the setting of an intracellular infectious process such as tuberculosis, it is conceivable that the airway may acidify in an effort to kill the organism during extracellular transit. We speculate that this transient acidification may be one mechanism used by humans to prevent the establishment of tuberculosis and other pathogens in the lungs.

\section{Acknowledgements}

The funding for this project was received from the Henry B. Wallace Foundation. This foundation did not participate in the research or manuscript preparation, and had no control over the product of this research. 


\section{References}

Acevedo, F. (2005). Exhaled breath condensate (EBC): changes in magnesium, pH and conductivity after exposure to swine hours dust or inhaled LPS. Eur Respir J, 26(49), P4669.

Acevedo, M., \& Steele, L. W. (1993). Na(+)-H+ exchanger in isolated epithelial tracheal cells from sheep. Involvement in tracheal proton secretion. Exp Physiol, 78(3), 383-394.

Appelberg, R. (1994). Protective role of interferon gamma, tumor necrosis factor alpha and interleukin-6 in Mycobacterium tuberculosis and M. avium infections. Immunobiology, 191(4-5), 520-525.

Bunyan, D., Smith, A., Davidson, W., Yu, Y., Urban, P., Naccara, L., Platts-Mills, J., \& Hunt, J. (2005). Correlation of exhaled breath condensate $\mathrm{pH}$ with invasively measured airway $\mathrm{pH}$ in the cow. Eur Respir J, 26(49), 2407.

Chicurel, M., Garcia, E., \& Goodsaid, F. (1988). Modulation of macrophage lysosomal pH by Mycobacterium tuberculosis-derived proteins. Infect Immun, 56(2), 479-483.

Crowle, A. J., Dahl, R., Ross, E., \& May, M. H. (1991). Evidence that vesicles containing living, virulent Mycobacterium tuberculosis or Mycobacterium avium in cultured human macrophages are not acidic. Infect Immun, 59(5), 1823-1831.

Fischer, H., Widdicombe, J. H., \& Illek, B. (2002). Acid secretion and proton conductance in human airway epithelium. Am J Physiol Cell Physiol, 282(4), C736-743.

Gomes, M. S., Paul, S., Moreira, A. L., Appelberg, R., Rabinovitch, M., \& Kaplan, G. (1999). Survival of Mycobacterium avium and Mycobacterium tuberculosis in acidified vacuoles of murine macrophages. Infect Immun, 67(7), 3199-3206.

Horvath, I., Hunt, J., \& Barnes, P. J. (2005). Exhaled breath condensate: methodological recommendations and unresolved questions. Eur Respir J, 26(3), 523-548.

Hunt, J. (2007). Exhaled Breath Condensate pH Assays. Immunol Allergy Clin North Am, 27(4), 597-606.

Hunt, J., Yu, Y., Burns, J., Gaston, B., Ngamtrakulpanit, L., Bunyan, D., Walsh, B. K., Smith, A., \& Hom, S. (2006). Identification of acid reflux cough using serial assays of exhaled breath condensate pH. Cough, 2, 3.

Hunt, J. F., Erwin, E., Palmer, L., Vaughan, J., Malhotra, N., \& Platts-Mills, T. A. E. (2002). Expression and activity of pH-regulatory glutaminase in the human airway epithelium. Am J Respir Crit Care Med, 165, 101-107.

Jack, C. I., Calverley, P. M., Donnelly, R. J., Tran, J., Russell, G., Hind, C. R., \& Evans, C. C. (1995). Simultaneous tracheal and oesophageal $\mathrm{pH}$ measurements in asthmatic patients with gastro-oesophageal reflux. Thorax, 50(2), 201-204.

Krause, K. H. (2000). Professional phagocytes: predators and prey of microorganisms. Schweiz Med Wochenschr, 130(4), 97-100.

Paget-Brown, A. O., Ngamtrakulpanit, L., Smith, A., Bunyan, D., Hom, S., Nguyen, A., \& Hunt, J. F. (2006). Normative data for $\mathrm{pH}$ of exhaled breath condensate. Chest, 129(2), 426-430.

Piddington, D. L., Kashkouli, A., \& Buchmeier, N. A. (2000). Growth of Mycobacterium tuberculosis in a defined medium is very restricted by acid $\mathrm{pH}$ and $\mathrm{Mg}(2+)$ levels. Infect Immun, 68(8), 4518-4522.

Rabinovich, M., DeStefano, M. J., \& Dziezanowski, M. A. (1980). Neutrophil migration under agarose: stimulation by lowered medium $\mathrm{pH}$ and osmolality. J Reticuloendothel Soc, 27(2), 189-200.

Sturgill-Koszycki, S., Schlesinger, P. H., Chakraborty, P., Haddix, P. L., Collins, H. L., Fok, A. K., Allen, R. D., Gluck, S. L., Heuser, J., \& Russell, D. G. (1994). Lack of acidification in Mycobacterium phagosomes produced by exclusion of the vesicular proton-ATPase [see comments] [published erratum appears in Science 1994 Mar 11;263(5152):1359]. Science, 263(5147), 678-681.

Trevani, A. S., Andonegui, G., Giordano, M., Lopez, D. H., Gamberale, R., Minucci, F., \& Geffner, J. R. (1999). Extracellular acidification induces human neutrophil activation. J Immunol, 162(8), 4849-4857.

Vaughan, J., Ngamtrakulpanit, L., Pajewski, T. N., Turner, R., Nguyen, T. A., Smith, A., Urban, P., Hom, S., Gaston, B., \& Hunt, J. (2003). Exhaled breath condensate $\mathrm{pH}$ is a robust and reproducible assay of airway acidity. Eur Respir J, 22(6), 889-894. 
Wu, C. W., Schmoller, S. K., Shin, S. J., \& Talaat, A. M. (2007). Defining the stressome of Mycobacterium avium subsp. paratuberculosis in vitro and in naturally infected cows. J Bacteriol, 189(21), 7877-7886.

Zigmond, S. H., \& Hargrove, R. L. (1981). Orientation of PMN in a pH gradient: acid-induced release of a chemotactic factor. J Immunol, 126(2), 478-481.

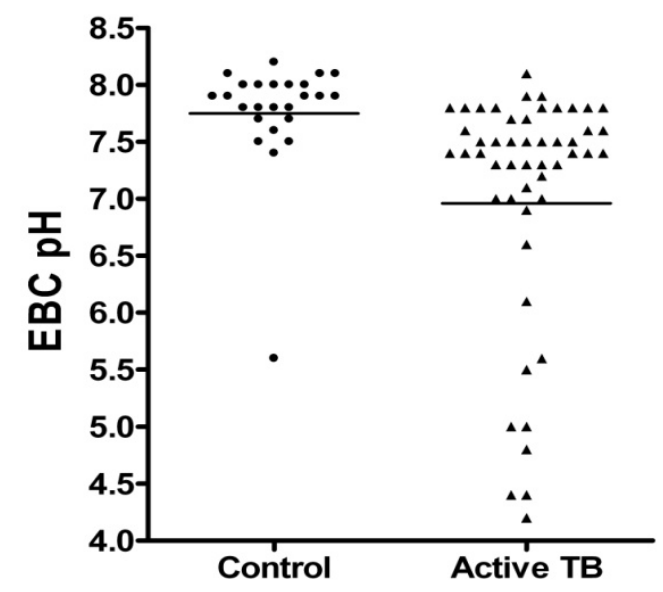

Figure 1. Exhaled breath condensate $\mathrm{pH}$ measurements obtained in Ghana and Thailand reveal airway acidity in patients with pulmonary tuberculosis

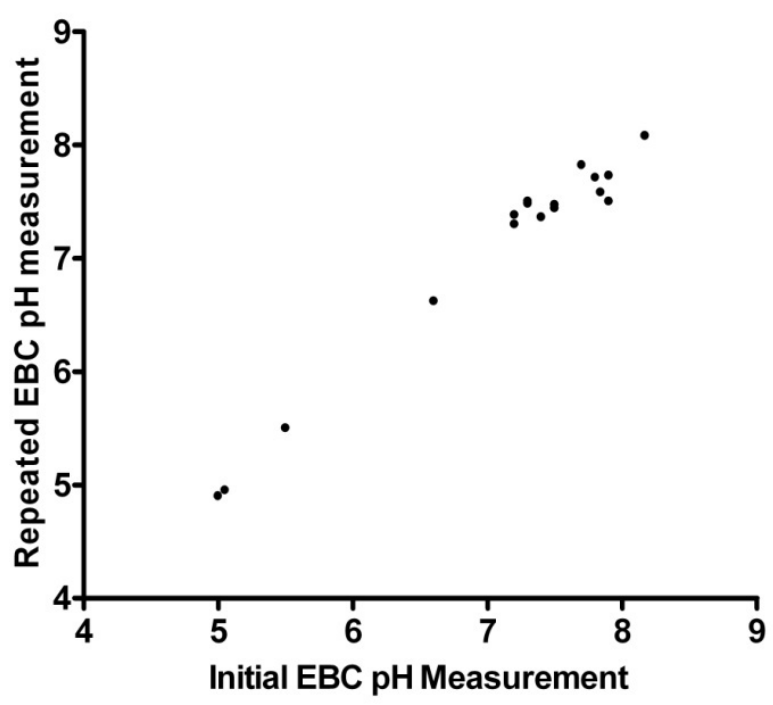

Figure 2. Exhaled breath condensate $\mathrm{pH}$ measurements from Ghana and Thailand were reproducible over time (same samples, repeated assays) 